\title{
Forming of Ceramic Laminates Comprising Thin Layers of a Few Particles
}

\author{
Ilias Nicolaidis, ${ }^{\ddagger}$ Jonas Gurauskis, ${ }^{\S}$ Carmen Baudín, Rodrigo Moreno, and A. Javier Sánchez-Herencia ${ }^{\dagger}$ \\ Ceramics Department, Instituto de Cerámica y Vidrio-CSIC, 28049 Madrid, Spain
}

In this paper, a water-based colloidal processing method for manufacturing multilayers with very thin zirconia layers between thick alumina-based layers is presented. The procedure involves the dip coating of green tapes in binder-containing slurries and further lamination and sintering. Dipping studies show that thickness increases with soaking time until a higher limit is achieved, indicating the existence of interaction between slurry and substrate. After sintering, homogeneous, dense, and continuous zirconia layers with thicknesses between 3 and $0.8 \mu \mathrm{m}$ alternated with $350 \mu \mathrm{m}$ layers of alumina are obtained, thus meaning that the cross section of these thin layers range from four or five to only one or two grains. Although the residual stresses are estimated to be around $2 \mathrm{GPa}$, indentation cracks do not shown any interaction when passing through the compressive layers, indicating the existence of a lower thickness limit to achieve a threshold stress.

\section{Introduction}

$\mathrm{T}$ HE design of laminated ceramics for emerging applications requires the control of the composition and thickness of the constituent layers. For devices such as solid oxide fuel cells (SOFC), thermal barrier coatings (TBC), or corrosion protective coatings, thin layers are increasingly needed to achieve higher efficiency. For instance, in the SOFCs, the ohmic contribution is large due to the high electrolyte resistance. It has been shown that ohmic polarization at intermediate temperature $\left(700^{\circ}-800^{\circ} \mathrm{C}\right)$ drastically decreases with the thickness of the electrolyte dense layer. ${ }^{1}$ Consequently the starting designs of electrolyte supported cells have changed to the cathode supported cells and the anode-supported cells with lower thicknesses (30-40 and 10-20 $\mu \mathrm{m}$, respectively). ${ }^{2}$ Ceramic laminates have also demonstrated to be an effective reinforcing route to overcome the intrinsic brittleness of ceramics. ${ }^{3-6}$ In this sense, compressive stresses are usually required as they oppose to the starting crack growth and/or may develop a threshold strength to be surpassed by the growing crack. ${ }^{6-9}$ The capability to stop the fracture crack and the development of a threshold strength has been described as a phenomenon associated with the compressive stresses in ceramic multilayers. ${ }^{6,10,11}$ The stress needed to extend a crack through a thin layer under compression $\left(\sigma_{\text {thr }}\right)$ is given by

E. Suvaci-contributing editor

Manuscript No. 23916. Received October 30, 2007; approved March 6, 2008

This work was supported by Ministerio de Educación y Ciencia, (Spain) under contract MAT 2006-01038

Author to whom correspondence should be addressed. e-mail: ajsanchez@icv.csic.es

${ }^{\ddagger}$ Current address: Rolls Royce Fuel Cell Systems Ltd., Loughborough, U.K

${ }^{\S}$ Instituto de Ciencia de Materiales de Aragón-CSIC, Zaragoza, Spain.

$$
\begin{aligned}
\sigma_{\mathrm{thr}}= & \frac{K_{\mathrm{c}}}{\sqrt{\pi \frac{t_{2}}{2}\left(1+\frac{2 t_{1}}{t_{2}}\right)}}+\sigma_{\mathrm{c}} \\
& \times\left(1-\left(1+\frac{t_{1}}{t_{2}}\right) \frac{2}{\pi} \sin ^{-1}\left(\frac{1}{1+\frac{2 t_{1}}{t_{2}}}\right)\right)
\end{aligned}
$$

where $K_{\mathrm{C}}$ is the fracture toughness of the thin layer, $t_{1}$ and $t_{2}$ are the thicknesses of the thin and thick layers respectively, and $\sigma_{\mathrm{c}}$ is the residual compressive stress. From this equation it can be inferred that the magnitude of the threshold stress and consequently the capability to stop a crack, for a given compressive stress, decreases with the thickness of the layers. In contrast to the benefits of layers under high compression, the associated tensile stresses in the laminates can generate tunneling cracks that reduce the integrity of ceramics, ${ }^{12,13}$ independently of the use or application.

In ceramic laminates with strong interfaces the strain differences $(\Delta \varepsilon)$ between layers are required to develop the residual stresses. These are achieved using either the differences between the coefficient of thermal expansion ${ }^{6,14}$ (CTE) or the expansion associated to the $t-m$ zirconia phase transformation during cooling. ${ }^{15,16}$ Regarding the last, variable differential strain between layers can be arisen by using variable amounts of unstabilized zirconia inside an alumina matrix, $, 9,17$ or adding stabilizers to the zirconia compacts. ${ }^{10,18}$ The critical role to the thickness ratios over the residual stresses values can be easily explained using the simplified model of an infinite plate. ${ }^{6,12,19}$ In a multilayer system with $n$ tensile layers with a thickness $t_{\mathrm{a}}$ alternated by $(n-1)$ compressive layers of thickness $t_{\mathrm{b}}$, and considering $n \gg 1$, the residual tensile and compressive stresses are interrelated by

$$
\sigma_{\mathrm{a}}=-\sigma_{\mathrm{b}} \frac{t_{\mathrm{b}}}{t_{\mathrm{a}}}
$$

From this basic formula it can be deduced that if $t_{\mathrm{b}} \ll t_{\mathrm{a}}$ then $\sigma_{\mathrm{a}} \rightarrow 0$, i.e., if thin layers are alternated with thick ones, the stresses inside the latter are negligible while the stresses inside the thins are still important. Indentation test through the cross section of a multilayer has been used elsewhere to evaluate the residual stresses ${ }^{20-22}$ (see references for a scheme). Cracks analysis after indentation has shown that on a tensile stressed layer, cracks running perpendicular to the layers direction are longer than parallel ones. Conversely, indentation cracks length on layers under compression show the opposite behavior.

Hence, fabrication of laminated materials with very thin layers is in focus and requires the development of simple and innovative processing strategies able to produce defect-free, uniform layers integrated in complex structures. Among the processing techniques developed to fabricate layered ceramics from precursors or from powder processing techniques ${ }^{23,24}$ dip coating has 
been extensively used in the sol-gel technology to produce thin functional coatings onto ceramic, glass, and metallic substrates. $^{25,26}$ The consolidation of a coating layer by dipping is achieved by the deposition and evaporation of the liquid, although it can also be assisted by an external force like filtration or electrophoretic deposition. ${ }^{26-28}$ The thickness of the films fabricated by dip coating can vary from nanometers to a few tens of micrometers depending on substrate parameters (wettability, roughness, and porosity), sol/suspension parameters (viscosity, solid content, binders content, and surface tension), and specific processing parameters (withdrawal rate, soaking time, temperature, and humidity). ${ }^{29-31}$ For a Newtonian slurry, the thickness of the layer $(h)$ can be calculated by the LandauLevich equation. $^{32}$

$$
h=0.94 \frac{(\eta \cdot v)^{2 / 3}}{\gamma_{\mathrm{LV}}^{1 / 6}(\rho \cdot g)^{1 / 2}}
$$

where $\eta$ is the viscosity of the slurry, $v$ is the withdrawal rate, $\gamma_{\mathrm{LV}}$ is the liquid-vapor surface tension, $\rho$ is the density of the slurry, and $g$ is the gravity.

Previous work demonstrated that layered ceramics with thin and thick alternating layers can be fabricated by a water-based colloidal route involving the dip coating of green tapes. ${ }^{33}$ The thickness of the coating on the green tape was different on each face of the tape due to the different porosity between the top and the bottom surfaces of the tape. ${ }^{28}$ In addition to dipping there is also a filtration process of the slurry through the open porosity of the tape as in the slip casting. ${ }^{34}$

In this paper, the manufacture of multilayered ceramics combining very thin layers of pure zirconia (without phase stabilizers) and thick layers with very low tensile residual stresses is studied. The method implies the saturation of the tape with water before immersion into the slurry. In this way, any possible filtration contribution to the coating thickness is avoided and only dip-coating parameters must be taken into account. The dip-coated tapes are used to build up a multilayer material that alternates thin zirconia layers (from $3 \mu \mathrm{m}$ to $<1 \mu \mathrm{m}$ ) with thick alumina ones $(350 \mu \mathrm{m})$. The interaction of a crack produced by Vicker indentation with the thin layer under compression is also studied.

\section{Experimental Procedure}

The substrates to be coated were produced by the doctor blade method using concentrated aqueous suspensions of a mixture of $\mathrm{Al}_{2} \mathrm{O}_{3}$ (HPA05, Ceralox, $d_{50}=0.35 \mu \mathrm{m}$ and $S_{\mathrm{s}}=9.5 \mathrm{~m}^{2} / \mathrm{g}$ ) with $5 \mathrm{vol} \%$ of tetragonal zirconia polycrystalline with $3 \mathrm{~mol} \%$ yttria (Y-TZP, TZ3YS, Tosoh, Japan, $d_{50}=0.4 \mu \mathrm{m}$ and $S_{\mathrm{s}}=6.5 \mathrm{~m}^{2} /$ $\mathrm{g}$ ), which was added to avoid exaggerated grain growth of alumina. Suspensions were prepared to $50 \mathrm{vol} \%$ solids in DI water using a $0.8 \mathrm{wt} \%$ (on a dry powder basis) of a polyelectrolyte (Dolapix CE-64 Zschimer-Schwarz, Burgstädt, Germany). Slurries were ball milled for $4 \mathrm{~h}$ using alumina jar and balls. For tape casting a $5 \mathrm{wt} \%$ (with regard to solids) of binder was added to the suspension and stirred for $30 \mathrm{~min}$ before casting. The binder was a polyacrylate/styrene emulsion (DM765E, Celanese, Spain) with solid content of $50 \mathrm{vol} \%$, particle size ranging between 0.05 and $0.15 \mu \mathrm{m}$, and $T_{\mathrm{g}}=-6^{\circ} \mathrm{C}$. The manufacture of these green tapes has been described elsewhere. ${ }^{19}$

Dry substrates were obtained by punching out disks of $2.5 \mathrm{~cm}$ in diameter from the green tapes after complete drying at $60^{\circ} \mathrm{C}$. Substrates were immersed in DI water until saturation, i.e., no weight gain was observed. Coatings were prepared by dipping either the dry or wet green substrates into pure zirconia (TZ-0, Tosoh, Japan, $d_{50}=0.3 \mu \mathrm{m}, S_{\mathrm{s}}=14.6 \mathrm{~m}^{2} / \mathrm{g}$ ) slurries which were prepared to solids contents of 30,15 , and $7.5 \mathrm{vol} \%$ containing $0.8 \mathrm{wt} \%$ of dispersant and $5 \mathrm{wt} \%$ of binder. Dipping studies were carried out for soaking times of $0,60,180,360$, and $900 \mathrm{~s}$ $(0,1,3,6$, and $15 \mathrm{~min})$ and withdrawal rates of $1.8,2.7,3.7$, and
$4.8 \mathrm{~mm} / \mathrm{s}$. Coated tapes were left to dry at room conditions overnight and further weighted to calculate the mass variation per unit area. Reported data were the average of three measurements. Direct observation of the cross-section of coated green samples were made by scanning electron microscopy (FEG-SEM Hitachi S-4700, Tokyo, Japan) with the samples embedded in epoxy resin and soft polished with sandpaper.

Multilayered materials with five thick layers of $\mathrm{Al}_{2} \mathrm{O}_{3}-$ Y-TZP and four very thin layers of TZ-0 were prepared by lamination and pressing of two coated tapes alternating with three uncoated tapes. The stack was pressed at $18 \mathrm{MPa}$ using flat and parallel plates as reported before. ${ }^{8,19}$ Figure 1 shows an overall scheme of the lamination process.

Samples were sintered at $1550^{\circ} \mathrm{C} / 2 \mathrm{~h}$ (heating and cooling rates of $5^{\circ} \mathrm{C} / \mathrm{min}$ ). Cross sections were polished with diamond paste down to $1 \mu \mathrm{m}$ and thermally etched for SEM characterization and indentation tests. Vickers indentations were performed with loads of 49 and $98 \mathrm{~N}$ for $15 \mathrm{~s}$. Indentations were performed on the three intermediate thick layers at different distances from the zirconia compressed thin layers. Cracks parallel and perpendicular to the layers, were measured by optical microscopy in well-defined indentations. To calculate the $K_{\mathrm{I} C}$ five indentations were done. Finally the indented cross sections of the multilayers were coated with gold for SEM observation of the cracks.

\section{Results and Discussion}

Figure 2 shows the optical micrographs for cross sections of dry (a) and wet (b) tapes dip-coated using a 30 vol\% slurry at a withdrawal rate of $3.7 \mathrm{~mm} / \mathrm{s}$. On one hand, it can be observed that dry tapes yield much thicker layers than wet ones as a consequence of the filtration phenomena described in a previous work. ${ }^{28}$ In addition, coating formed on dry tapes show different thicknesses between opposite sides due to the different porosity between the upper and the bottom surfaces of the tape. The different thickness is more significant as the solid content of the slurries decreases. On the other hand, wet saturated substrates yield similar thicknesses in both sides. Table I summarizes the layer thicknesses measured directly by optical microscopy for dry and wet tapes coated with 30,15 , and $7.5 \mathrm{vol} \%$ slurries. All the dry tapes show a thicker coating than wet ones as well as the thickness difference between sides.

As the objective of the work is to obtain very thin compressive layers, further studies were devoted to optimize the 15 and 7.5 vol\% slurries using water-saturated substrates. This pretreatment assures that coatings thicknesses are almost homogenous on both sides and do not have any contribution due to filtration effects.

To evaluate the influence of soaking time and withdrawal rate on the thickness of the coating, disks were dip coated using a 15

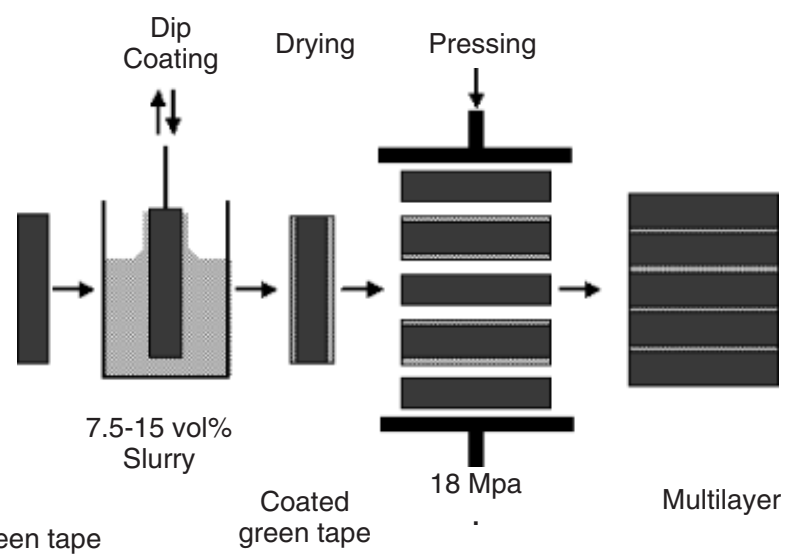

Fig. 1. Scheme of the dip-coating and piling processing steps that allows the fabrication of the multilayered ceramics. 

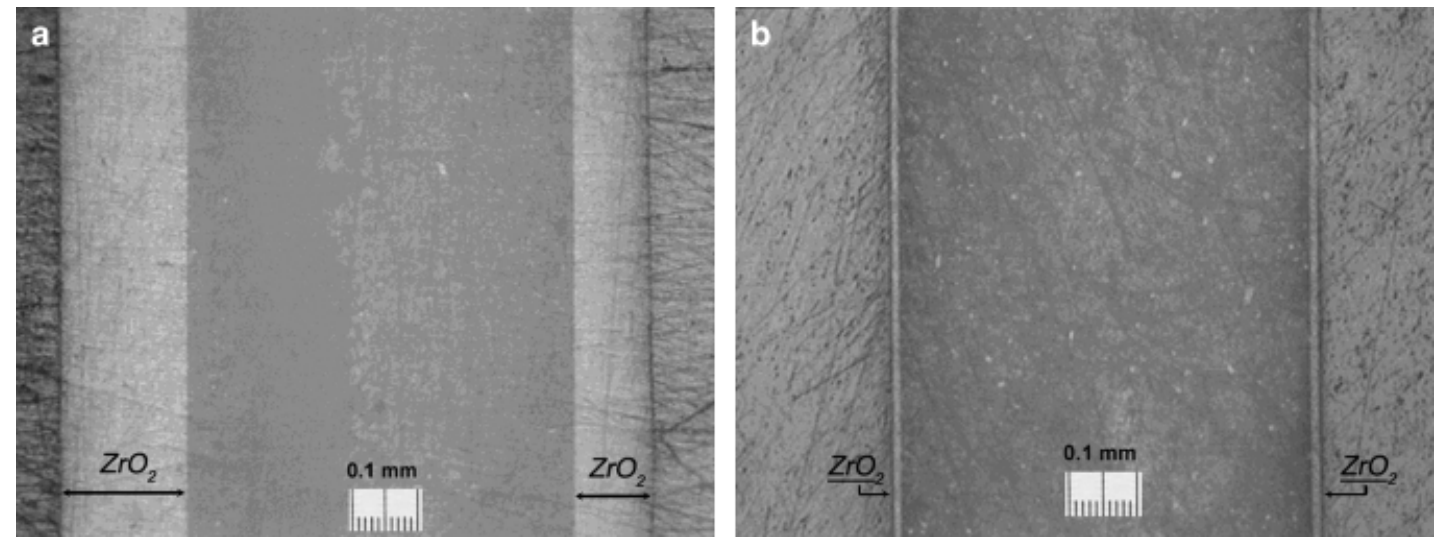

Fig. 2. Optical micrograph of the cross section of green coating obtained by dipping dry (a) and wet (b) tapes in a $30 \mathrm{vol} \%$ slurry.

vol\% solids TZ-0 slurry with soaking times from 0 to $900 \mathrm{~s}$ and withdrawal rates of $1.8,2.7,3.7$, and $4.8 \mathrm{~mm} / \mathrm{s}$. Figure 3 plots the mass per unit area of deposited material versus the soaking time for withdrawal rates of 1.8 and $4.8 \mathrm{~mm} / \mathrm{s}$. A similar trend was observed for the other rates but only those two are shown for simplicity. It is observed that the coating thickness increases with the soaking time until a limit is achieved for times longer than $180 \mathrm{~s}$. It can be also observed that for the same soaking time coatings are thicker as withdrawal rate increases, as expected (Eq. (3)). However, when withdrawal starts just after immersion, that is, zero soaking time, the thinnest coating corresponds to the highest withdrawal rate in opposition to the Landau-Levich equation. Assuming that all samples have a similar green density, the larger thickness obtained for larger soaking times suggests that there exists a time depending interaction between the binder-containing slurry and the substrate, because no filtration takes place with saturated wet substrates. Hence, there is a second contribution to the total thickness related to soaking time until a limit value is achieved. Longer soaking times do not produce further deposition of particles. This limit is reached later when coatings are built-up at lower withdrawal rate.

According to these results a constant soaking time of $180 \mathrm{~s}$ was then maintained in further experiments. The lowest withdrawal rate $(1.8 \mathrm{~mm} / \mathrm{s})$ was used to reach thinner coatings. Figure 4 shows the SEM microstructure of the cross sections of green tapes coated with zirconia slurries with 30,15 , and $7.5 \mathrm{vol} \%$ solids (Figs. 4(a)-(c) respectively). These pictures demonstrate the evident increase of thickness of the zirconia layer (bright phase) with solids loading. The thickness of the green coating varied between $14-15$ and $3.5-4$ and $0.5-1 \mu \mathrm{m}$ for the slurries with solids contents of 30,15 , and $7.5 \mathrm{vol} \%$, respectively. The last coating involves the presence of only three or four particles in the layer, so that thickness uniformity has a high relative error since the variation of only one particle leads to a relative error of $25 \%-33 \%$.

After piling up the coated and uncoated green tapes under low pressure, samples were sintered at $1550^{\circ} \mathrm{C} / 2 \mathrm{~h}$. Multilayers fabricated using the green tapes coated with the $15 \mathrm{vol} \%$

Table I. Summary of the Weigth Gain by Area and Thickness Measured on Dry and Wet Samples Dip Coated in Slurries with Different Solid Contents at a Withdrawal Rate of $3.7 \mathrm{~mm} / \mathrm{s}$

\begin{tabular}{|c|c|c|c|c|c|c|}
\hline \multirow{2}{*}{$\begin{array}{l}\text { Solids content } \\
\text { Tape pretreatment }\end{array}$} & \multicolumn{2}{|c|}{$30 \mathrm{vol} \%$} & \multicolumn{2}{|c|}{$15 \mathrm{vol} \%$} & \multicolumn{2}{|c|}{$7.5 \mathrm{vol} \%$} \\
\hline & Dry & Wet & Dry & Wet & Dry & Wet \\
\hline $\begin{array}{l}\text { Weight gain }\left(\mathrm{mg} / \mathrm{mm}^{2}\right) \\
\text { Thickness }(\mu \mathrm{m})\end{array}$ & 0.39 & 0.07 & 0.11 & 0.0067 & 0.047 & 0.0036 \\
\hline Bottom & 210 & 12 & 44 & 3.5 & 30.5 & $<1$ \\
\hline Top & 97 & 11 & 5.8 & 3.3 & 6.2 & $<1$ \\
\hline
\end{tabular}

(Fig. 4(b)) slurries were named as $15 \mathrm{M}$, while multilayers obtained from $7.5 \mathrm{vol} \%$ coatings (Fig. 4(c)) were named as $7.5 \mathrm{M}$. Figure 5 shows the cross-sectional microstructure of laminates 15M (Fig. 5(a)) and 7.5M (Fig. 5(b)) that includes a close-up to the thin-layer area. Within any laminate the zirconia layers do not show relevant thickness changes and are perfectly joined to the tape, showing very sharp interfaces. The binder used in the dipping slurry formulation ensures a good adhesion of the coating to the substrate. ${ }^{8,19}$ In the case of the $7.5 \mathrm{M}$ samples, the multilayered structure cannot be easily appreciated in a so general view, due to the large difference in thickness between the thick layers of $\mathrm{Al}_{2} \mathrm{O}_{3} / \mathrm{Y}-\mathrm{TZP}$, with an average thickness of $350 \pm 20 \mu \mathrm{m}$, and the thinner TZ0 layers with $<1 \mu \mathrm{m}$ in thickness. Neither discontinuities, nor delaminations or cracks were appreciated in the thin layers after sintering, even when alumina and zirconia have very different sintering behavior. ${ }^{19}$ Some experiments performed at short soaking times (below $60 \mathrm{~s}$ in Fig. 3) generated thin layers composed of a row of just one particle, but some discontinuities occurred along the layer.

The porosity of the different layers in the multilayer was very low, indicating that a high densification level was achieved. The average thickness measured in the four thin layers was $0.8 \pm 0.1$ and $2.8 \pm 0.5 \mu \mathrm{m}$ for the laminates 7.5 and $15 \mathrm{M}$, respectively. It can be observed that $7.5 \mathrm{M}$ layers contain only one or two grains, while the $15 \mathrm{M}$ layer is composed by three to five grains of variable sizes.

Considering the martensitic transformation of zirconia and the thicknesses measured in the laminates, the residual stresses were estimated to be $\approx 2 \mathrm{GPa}$ in the zirconia layer whereas the associated tensile stress in the alumina layers range between 2

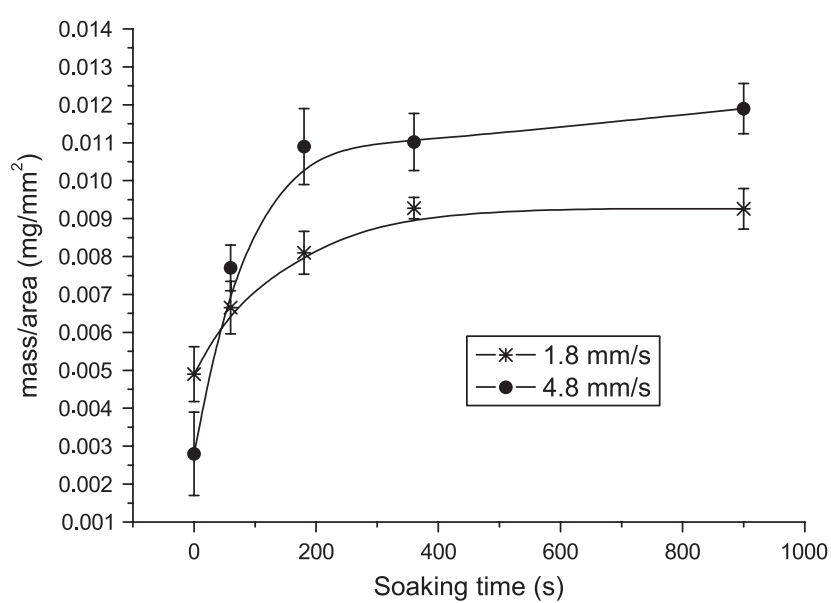

Fig. 3. Variation of mass per unit area with soaking time for coatings prepared with a $15 \mathrm{vol} \%$ slurry at two different withdrawal rates. 

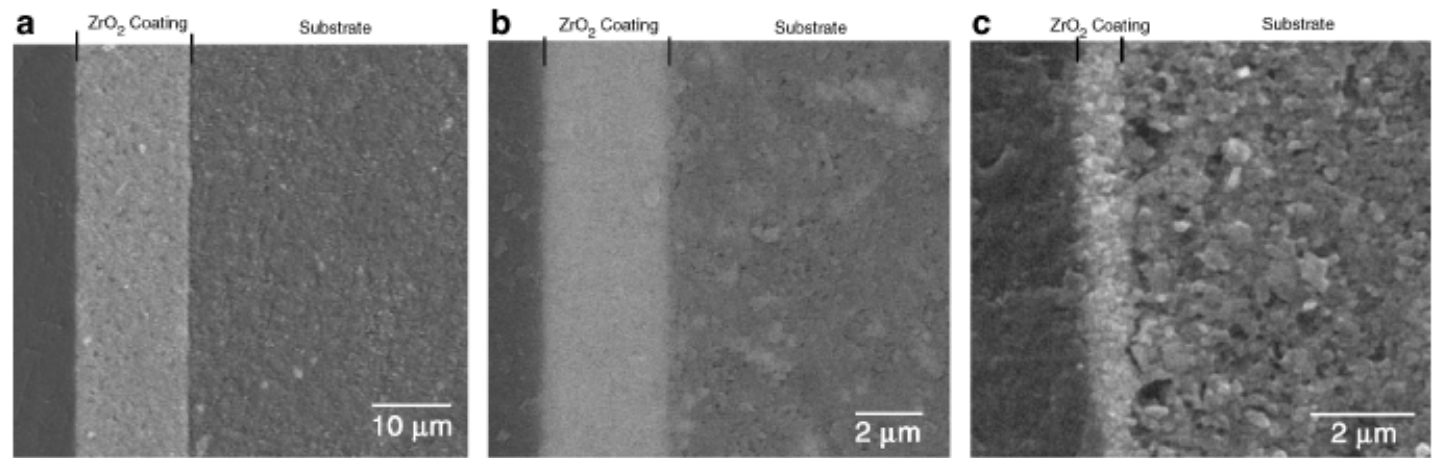

Fig. 4. Scanning electron microscopy pictures of the cross section of green tapes coated by dipping in slurries with solid contents of $30 \mathrm{vol} \%$ (a), 15 vol\% (b) and $7.5 \mathrm{vol} \%$ (c) for soaking times of $180 \mathrm{~s}$.

and $14 \mathrm{MPa}$ for the 7.5 and $15 \mathrm{M}$ samples, respectively. ${ }^{9,10,18}$ These residual tensions should not have a significant effect on the crack length of indentations performed on the alumina layers. The experimental indentations confirm this prediction and no differences between parallel and perpendicular lengths of the cracks could be appreciated. The $K_{\mathrm{IC}}$ calculated according to the Anstis formula ${ }^{35}$ was of $3.1 \pm 0.4 \mathrm{MPa} \cdot \mathrm{m}^{1 / 2}$ for sample $15 \mathrm{M}$ and $2.9 \pm 0.2$ for sample $7.5 \mathrm{M}$. All these data were included in Eq. (1) to calculate a threshold strength of around
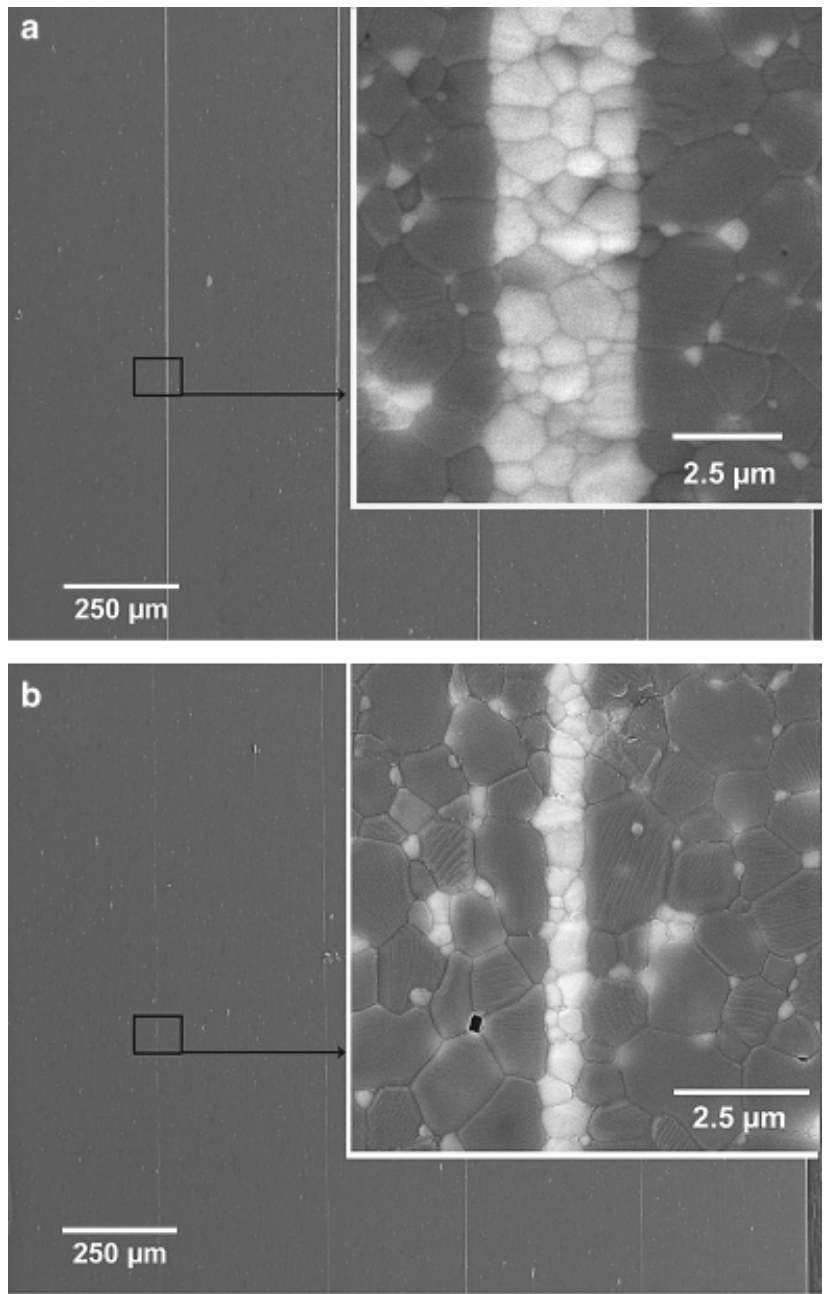

Fig. 5. Mutilayered ceramics with alternative thick alumina layers (dark phase) and thin zirconia layers (bright lines). (a) From 15 vol\% coating slurries with an average thickness of about $2.8 \mu \mathrm{m}$ (4-5 grains). (b) From $7.5 \mathrm{vol} \%$ coating slurries with an average thickness of about $0.8 \mu \mathrm{m}$ (1-2 grains).
$587 \mathrm{MPa}$ that is consistent to other values calculated for similar laminates. ${ }^{10}$ Figure 6 shows an indentation performed on the layer of alumina of a $15 \mathrm{M}$ layer. No special difference is observed between the length of parallel and perpendicular cracks. Moreover, the crack path seems not to be affected by the presence of the zirconia layer. This is an indicative of two important facts. Firstly that joining between layers is coherent and neither delamination nor deflection is appreciated. Figures 7(a) and (b) shows the close up to the area of intersection between crack and compressive layers for the materials with two different thickness ratio. Except a small change in the direction through the interface, no significant change in the growing behavior is observed in spite of the very high compressive stress level. This is in agreement with Eq. (1), which establishes that the lower is the thickness of the thin compressive layer, the lower is the threshold stress required by the crack to pass through. Previous works with layers thicker than $10 \mu \mathrm{m}$ have shown that layers under compression can stop a crack or change the growing direction. ${ }^{18}$ This is the first demonstration that below a certain limit thickness the reinforcement of the compressive layers is not relevant, but further fracture studies with bending and tensile test are required to corroborate this idea.

\section{Conclusions}

Dipping of water saturated green tapes into binder containing slurries yield to homogeneous coatings of different thicknesses

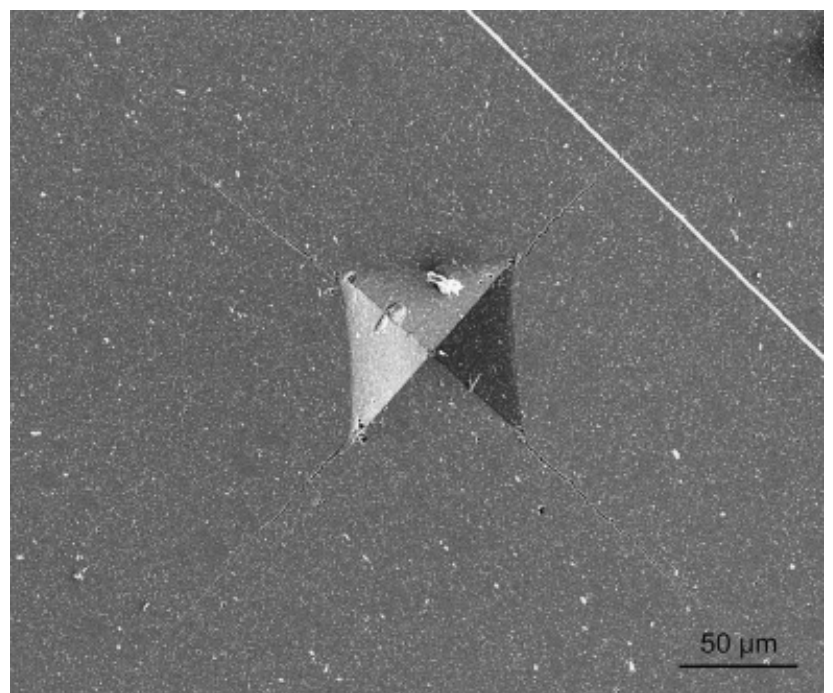

Fig. 6. Indentation on a alumina layer. No significant difference between crack lengths can be observed. It should be noted that crack interaction with the $\mathrm{ZrO}_{2}$ layer do not provide any effect on the crack growth. 

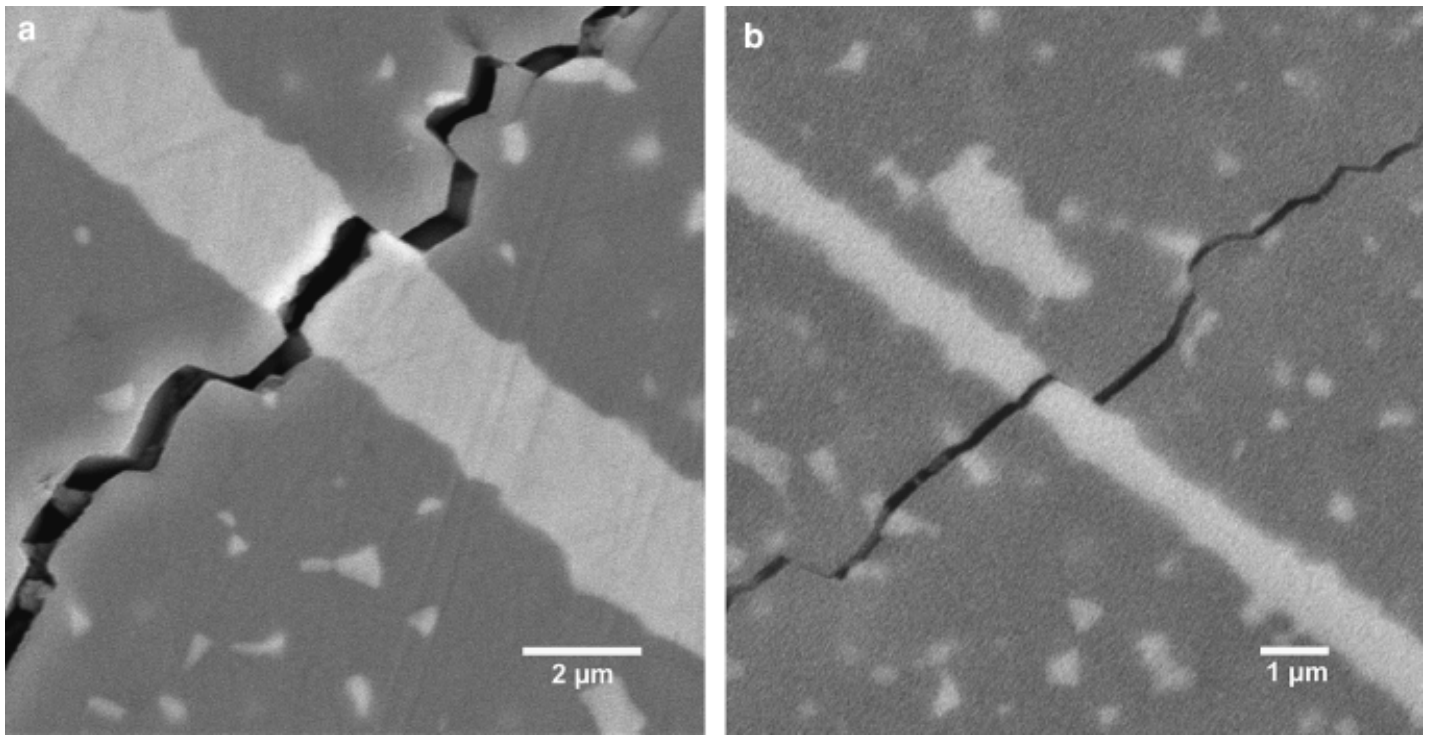

Fig. 7. Close up to the intersection of the crack growing through the alumina layer with the pure zirconia thin layer on the $15 \mathrm{M}$ (a) and $7.5 \mathrm{M}$ (b) multilayers.

depending on the solids content of the slurry, the withdrawal rate and the immersion time. The thickness dependence on the immersion time indicates that a binding mechanism different to the deposition-evaporation is developed between particles in the slurry and substrate. Homogeneous and reliable coatings on the green tapes were piled, pressed and cosintered for the manufacturing of multilayered ceramics that combine very thick layers sandwiching layers as thin as $0.8 \mu \mathrm{m}$ (i.e., two or three particle diameter). Considering that the minimum layer thickness reached is about twice or three times the average particle diameter, it can be expected that this simple route could be applied to nanometric layers using aqueous based diluted suspensions of nanosized particles. This combination of different thicknesses is applicable in technologies such as SOFC or TBCs as they require designs that comprise very thin layers. The low thickness of the layers allows the fabrication of crack-free layers of monoclinic zirconia which very high compressive stresses have been estimated to be about $2 \mathrm{GPa}$. Although this high stress level should be enough to stop the crack no interaction has been observed between thin layers and indentation cracks, showing that a critical thickness has to be surpassed to reach an effective reinforcement. This indicate that achievement of an effective reinforcement by compressive layers the thickness of the thin layer should balance the residual tensile stress associated to the thick layer and the critical thickness.

\section{References}

${ }^{1}$ A. V. Akkaya, "Electrochemical Model for Performance Analysis of a Tubular SOFC," Int. J. Energy Res., 31 [1] 79-98 (2007).

${ }^{2}$ J. W. Kim, A. V. Virkar, K. Z. Fung, K. Mehta, and S. C. Singhal, "Polarization Effects in Intermediate Temperature, Anode-Supported Solid Oxide Fue Cells," J. Electrochem. Soc., 146 [1] 69-78 (1999).

${ }^{3}$ W. J. Clegg, K. Kendall, N. M. Alford, T. W. Button, and J. D. Birchall, "A Simple Way to Make Tough Ceramics," Nature, 347 [6292] 455-7 (1990)

${ }^{4}$ H. M. Chan, "Layered Ceramics: Processing and Mechanical Behavior," Annu. Rev. Mater. Sci., 27, 249-82 (1997).

${ }^{5}$ D. J. Green, R. Tandon, and V. M. Sglavo, "Crack Arrest and Multiple Cracking in Glass Through the Use of Designed Residual Stress Profiles," Science, 283 [5406] 1295-7 (1999)

${ }^{6}$ M. P. Rao, A. J. Sanchez-Herencia, G. E. Beltz, R. M. McMeeking, and F. F. Lange, "Laminar Ceramics that Exhibit a Threshold Strength," Science, 286 [5437] $102-5$ (1999).

${ }^{7}$ R. Tandon and D. J. Green, "Crack Stability and T-Curves Due to Macroscopic Residual Compressive Stress Profiles,” J. Am. Ceram. Soc., 74 [8] 1981-6 (1991).

${ }^{8}$ J. Gurauskis, A. J. Sanchez-Herencia, and C. Baudin, "Alumina-Zirconia Layered Ceramics Fabricated by Stacking Water Processed Green Ceramic Tapes," J. Eur. Ceram. Soc., 27 [2-3] 1389-94 (2007).
${ }^{9}$ R. Bermejo, C. Baudin, R. Moreno, L. Llanes, and A. J. Sanchez-Herencia, "Processing Optimisation and Fracture Behaviour of Layered Ceramic Composites with Highly Compressive Layers," Compos. Sci. Technol., 67 [9] 1930-8 (2007).

${ }^{10}$ M. G. Pontin, M. P. Rao, A. J. Sanchez-Herencia, and F. F. Lange, "Laminar Ceramics Utilizing the Zirconia Tetragonal-to-Monoclinic Phase Transformation to Obtain a Threshold Strength," J. Am. Ceram. Soc., 85 [12] 3041-8 (2002).

${ }^{11}$ R. Bermejo, Y. Torres, C. Baudin, A. J. Sanchez-Herencia, J. Pascual, M. Anglada, and L. Llanes, "Threshold Strength Evaluation on an $\mathrm{Al}_{2} \mathrm{O}_{3}-\mathrm{ZrO}_{2}$ Multilayered System," J. Eur. Ceram. Soc., 27 [2-3] 1443-8 (2007).

${ }^{12}$ C. Hillman, Z. Suo, and F. F. Lange, "Cracking of Laminates Subjected to Biaxial Tensile Stresses," J. Am. Ceram. Soc., 79 [8] 2127-33 (1996).

${ }^{13}$ A. J. Sánchez-Herencia, J. S. Moya, and A. P. Tomsia, "Microstructural Design in Alumina-Alumina/Zirconia Layered Composites," Scr. Mater., 38 [1] 1-5 (1997).

${ }^{14}$ M. Oechsner, C. Hillman, and F. F. Lange, "Crack Bifurcation in Laminar Ceramic Composites," J. Am. Ceram. Soc., 79 [7] 1834-8 (1996).

${ }^{15}$ R. A. Cutler, J. D. Bright, A. V. Virkar, and D. K. Shetty, "Strength Improvement in Transformation-Toughened Alumina by Selective Phase-Transformation," J. Am. Ceram. Soc., 70 [10] 714-8 (1987).

${ }^{16}$ J. S. Moya, J. A. Sanchez Herencia, J. F. Bartolome, and T. Tanimoto, "Elastic Modulus in Rigid $\mathrm{Al}_{2} \mathrm{O}_{3} / \mathrm{ZrO}_{2}$ Ceramic Laminates," Scr. Mater., 37 [7] 1095 103 (1997)

${ }^{17}$ A. V. Virkar, J. L. Huang, and R. A. Cutler, "Strengthening of Oxide Ceramics by Transformation-Induced Stresses," J. Am. Ceram. Soc., 70 [3] 164-70 (1987)

${ }^{18}$ A. J. Sanchez-Herencia, C. Pascual, J. He, and F. F. Lange, " $\mathrm{ZrO}_{2} / \mathrm{ZrO}_{2}$ Layered Composites for Crack Bifurcation," J. Am. Ceram. Soc., 82 [6] 1512-8 (1999)

${ }^{19}$ A. J. Sanchez-Herencia, J. Gurauskis, and C. Baudin, "Processing of $\mathrm{Al}_{2} \mathrm{O}_{3}$ Y-TZP Laminates from Water-Based Cast Tapes," Compos. Part B-Eng., 37 [6] 499-508 (2006).

${ }^{20}$ D. H. Park, Y. G. Jung, and U. Paik, "Evaluation of Residual Stress in $\mathrm{BaTiO}_{3}$-Based Ni-MLCCs with X7R Characteristics," J. Mater. Sci--Mater. Electron., 15 [4] 253-9 (2004).

${ }^{21}$ H. Moon, M. G. Pontin, and F. F. Lange, "Crack Interactions in Laminar Ceramics that Exhibit a Threshold Strength," J. Am. Ceram. Soc., 87 [9] 1694-700 (2004).

${ }^{22}$ R. Bermejo, Y. Torres, A. J. Sanchez-Herencia, C. Baudin, M. Anglada, and L. Llanes, "Fracture Behaviour of an $\mathrm{Al}_{2} \mathrm{O}_{3}-\mathrm{ZrO}_{2}$ Multi-Layered Ceramic with Residual Stresses Due to Phase Transformations," Fatigue Fract. Eng. Mater. Struct., 29 [1] 71-8 (2006).

${ }^{23}$ J. Will, A. Mitterdorfer, C. Kleinlogel, D. Perednis, and L. J. Gauckler, "Fabrication of Thin Electrolytes for Second-Generation Solid Oxide Fuel Cells," Solid State Ion, 131 [1-2] 79-96 (2000)

${ }^{24}$ A. J. Sanchez-Herencia, "Water Based Colloidal Processing of Ceramic Laminates," Key Eng. Mater., 333, 39-48 (2007).

${ }^{25}$ M. A. Villegas, M. Aparicio, and A. Duran, "Thick Sol-Gel Coatings Based on the $\mathrm{B}_{2} \mathrm{O}_{3}-\mathrm{SiO}_{2}$ System," J. Non-Cryst. Solids, 218, 146-50 (1997).

${ }^{26}$ Y. Castro, A. Duran, R. Moreno, and B. Ferrari, "Thick Sol-Gel Coatings Produced by Electrophoretic Deposition," Adv. Mater., 14 [7] 505-8 (2002).

${ }^{27}$ C. J. Brinker and A. J. Hurd, "Fundamentals of Sol-Gel Dip-Coating," J. Phys. III, 4 [7] 1231-42 (1994).

${ }^{28}$ M. G. Pontin, F. F. Lange, A. J. Sanchez-Herencia, and R. Moreno, "Effect of Unfired Tape Porosity on Surface Film Formation by Dip Coating," J. Am. Ceram. Soc., 88 [10] 2945-8 (2005). 
${ }^{29}$ C. W. Park, "Effects of Insoluble Surfactants on Dip Coating," J. Colloid Interface Sci., 146 [2] 382-94 (1991).

${ }^{30}$ S. Pellice, P. Galliano, Y. Castro, and A. Duran, "Hybrid Sol-Gel Coatings Produced from TEOS and Gamma-MPS," J. Sol-Gel Sci. Technol., 28 [1] 81-6 (2003).

${ }^{31}$ R. Krechetnikov and G. M. Homsy, "Experimental Study of Substrate Roughness and Surfactant Effects on the Landau-Levich Law," Phys. Fluids, 17 [10] 102108 (2005).

${ }^{32}$ L. D. Landau and B. G. Levich, "Dragging of a Liquid by a Moving Plate," Acta Physicochim. URS, 17, 42 (1942).
${ }^{33}$ M. G. Pontin and F. F. Lange, "Effects of Porosity on the Threshold Strength of Laminar Ceramics," J. Am. Ceram. Soc., 88 [2] 376-82 (2005).

${ }^{34}$ Y. F. Gu and G. Y. Meng, "A Model for Ceramic Membrane Formation by Dip-Coating," J. Eur. Ceram. Soc., 19 [11] 1961-6 (1999).

${ }^{35}$ G. R. Anstis, P. Chantikul, B. R. Lawn, and D. B. Marshall, "A Critical-Evaluation of Indentation Techniques for Measuring FractureToughness. 1. Direct Crack Measurements," J. Am. Ceram. Soc., 64 [9] 533-8 (1981). 